\footnotetext{
1. MBBS, FCPS (Orthopaedic). Associate professor Orthopaedic surgery Dow International Medical College Dow University of Health sciences, Karachi, Pakistan.

2. MBBS, FRCS, McH

Professor of Orthopaedic Surgery Dow International Medical College Dow University of Health Sciences, Karachi, Pakistan.

3. MBBS, FCPS (Orthopaedic) Assistant Professor Orthopaedic Surgery Dow International Medical College Dow University of Health Sciences, Karachi, Pakistan.

Correspondence Address: Dr. Ghulam Mustafa Kaim Khani MBBS, FCPS (Orthopaedic).

Associate professor Orthopaedic surgery

Dow International Medical College

Dow University of Health Sciences,

Karachi, Pakistan.

drkk58@hotmail.com

Article received on:

02/09/2014

Accepted for publication:

10/10/2014

Received after proof reading: $15 / 12 / 2014$
}

\section{PRIMARY DIAPHYSEAL TUBERCULOUS OSTEOMYELITIS OF TIBIA}

\section{Dr. Ghulam Mustafa Kaim Khan', Dr. Syed Mujahid Humail², Dr. Kamran Hafeez ${ }^{3}$}

ABSTRACT... Diaphyseal tubercular osteomyelitis of long bone is extremely rare and few cases have been reported in literature. We are presenting a case of 17 years old girl presented with pain and swelling over lower half of leg for 7 months. There was often low grade fever but no history of weight loss or pulmonary symptoms. X-ray chest was normal. X-rays and $\mathrm{MRI}$ of involved leg were suggestive of osteomyelitis. Curettage and biopsy was done, report was suggestive of tuberculous osteomyelitis. As tuberculosis is still common in developing countries, for an osteolytic lesion in bone, tuberculous osteomyelitis should be considered in differential diagnosis.

Key words: Diaphyseal tuberculosis; tuberculous osteomyelitis; Extra-pulmonary tuberculosis

Article Citation: Khan GMK, Humail SM, Hafeez K. Primary diaphyseal tuberculous osteomyelitis of tibia. Professional Med J 2014; 21(6):1282-1284.

\section{INTRODUCTION}

Tuberculosis of bone and joint is a rare disease caused by Myobacterium tuberculosis. It is primarily a disease of developing countries. Due to a pandemic of human immunodeficiency virus infection, tuberculosis is also seen in Europe and North America ${ }^{1}$. In 2010 approximately 8.8 million new cases of tuberculosis were reported and 1.45 million people died worldwide ${ }^{2}$. Tuberculosis in HIV infection is usually extra pulmonary. The incidence of skeletal manifestation in tuberculosis is very low, any bone can be affected, however spine is the most common site for skeletal TB, accounting more than $50 \%$ of all cases ${ }^{3,4}$ followed by femur, tibia and fibula. Tuberculous osteomyelitis is secondary to lymphohaematogenous spread with lung being the primary focus in $75 \%$ of cases 5 . Osteoarticular tuberculous is a rare form of disease accounting for $1-5 \%$ of all cases ${ }^{6}$. Large weight bearing joints, long bones, skull and soft tissues can be involved. Primary diaphyseal TB of long bone is extremely rare and only few cases have been reported in literature ${ }^{7}$. Clinical symptoms may be mild and the diagnosis of tuberculous osteomyelitis requires a high degree of suspicion for accurate and timely diagnosis. Identification of mycobacterium tuberculosis with culture is a lengthy process, causing delay in the accurate diagnosis. Turgutetal ${ }^{8}$ reported an average delay in the diagnosis of tuberculous osteomyelitis of 6.6 months. Biopsy and histopathology evaluation are more useful for early diagnosis.

\section{CASE REPORT}

A 17 year old girl presented in our clinic with the history of pain in the lower half of leg for last 7 months. Pain was mild in intensity, increased during walking and relieved with rest. There was history of low grade fever. She also noticed a small painful swelling in lower half of leg. There was no history of trauma, cough or weight loss. There was no history of tuberculosis in the family. BCG vaccination was performed in childhood. She belonged to lower middle class family, was young, intelligent and well-nourished. Examination of lower leg revealed diffuse, tender swelling $5 \times 8 \mathrm{~cm}$ in size and local temperature was normal. X-ray lower tibia showed osteolytic lesion $1 \mathrm{~cm}$ in diameter, at junction of upper two third and lower one third of tibia (Figure-1). MRI lower leg showed abnormal high intensity signals in the lower one third of tibia involving diaphysis associated with mild expansion and erosion of the lateral cortex (Figure-2). Mantoux test was positive, erythrocyte sedimentation rate was $30 \mathrm{~mm} /$ hour, and CRP was 25 . X-Ray chest was normal. Chronic pyogenic osteomyelitis was provisionally diagnosed and after consent 
of patient and her parents, curettage with biopsy was done. Histopathology report was suggestive of tuberculous osteomyelitis (Figure $3 \& 4$ ). After curettage and biopsy report, anti tuberculous therapy was started with four drugs regimen. Rifampicin $10 \mathrm{mg} / \mathrm{kg} /$ day, Pyrazinamide $35 \mathrm{mg} /$ $\mathrm{kg} /$ day, Isoniazid $5 \mathrm{mg} / \mathrm{kg} /$ day and Ethambutol $25 \mathrm{mg} / \mathrm{kg} / \mathrm{day}$ and vitamin B-6 was started for initial two months and then Rifampicin, Isoniazid and vitamin B-6 continued for another twelve months. Clinically patient improved significantly after curettage and anti-tubercular drugs. $X$ ray showed good healing at 12 months (Figure-5).

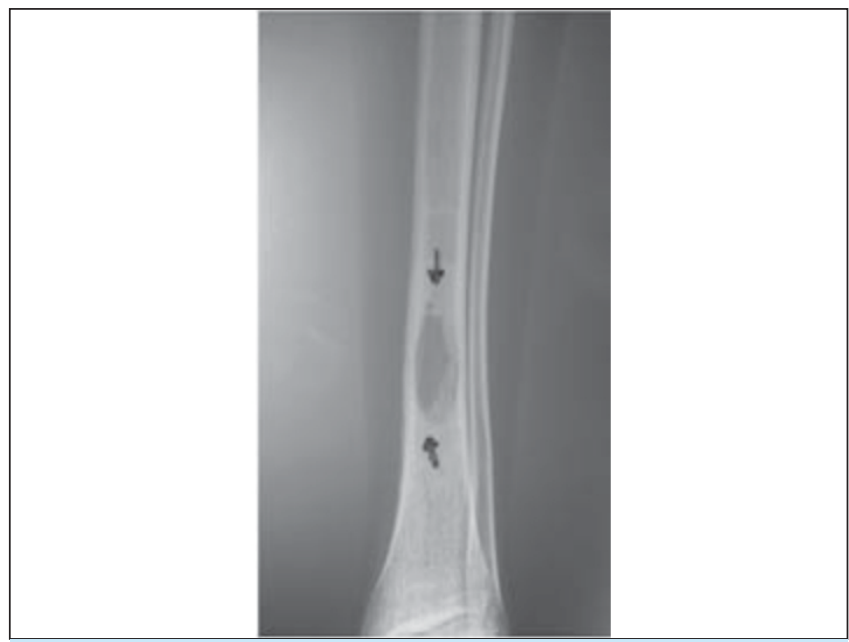

Fig-1. Preoperative X-Ray of tibia showing a lytic lesion in diaphysis

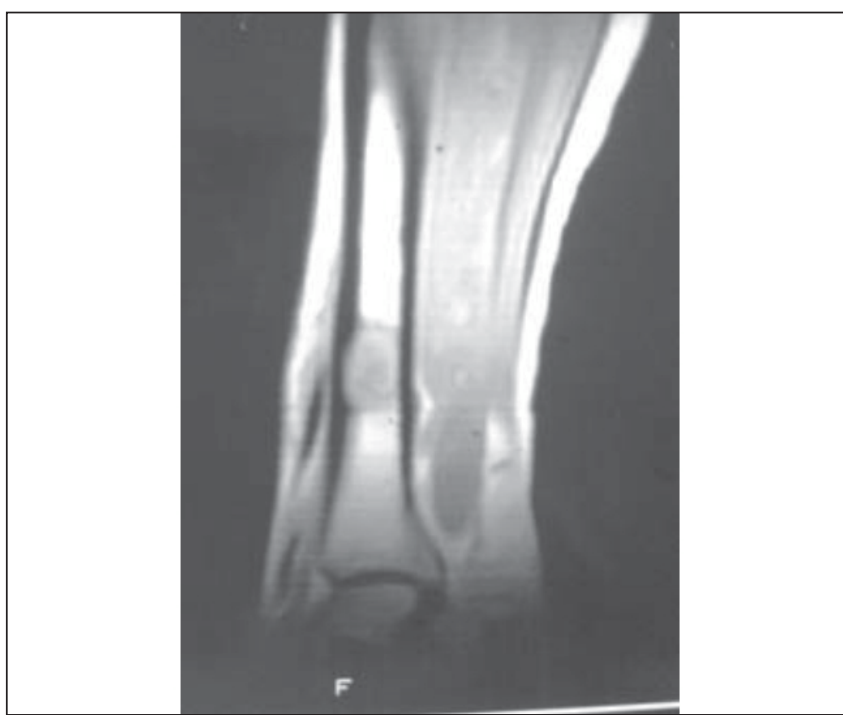

Fig-2. MRI of involved leg showing a lesion in the lower third of tibia

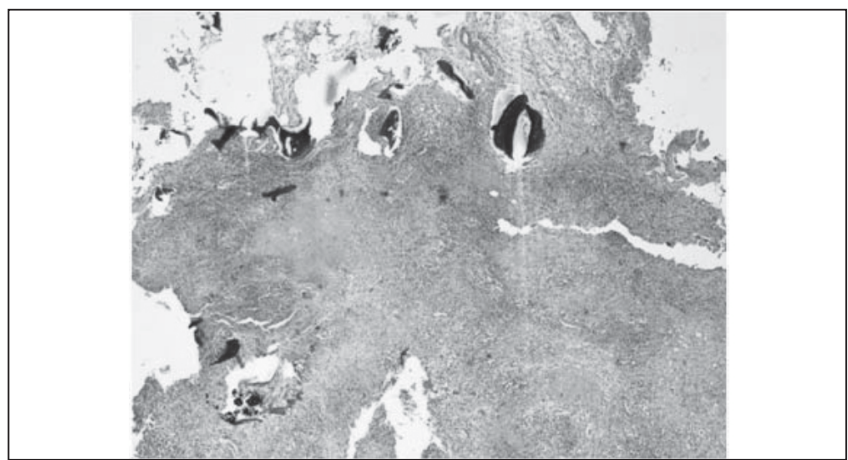

Fig-3. The low power view of histological image of affected bone with granulomatous inflammation along with foci of central caseation type necrosis. (hematoxylin and eosin, 10x)

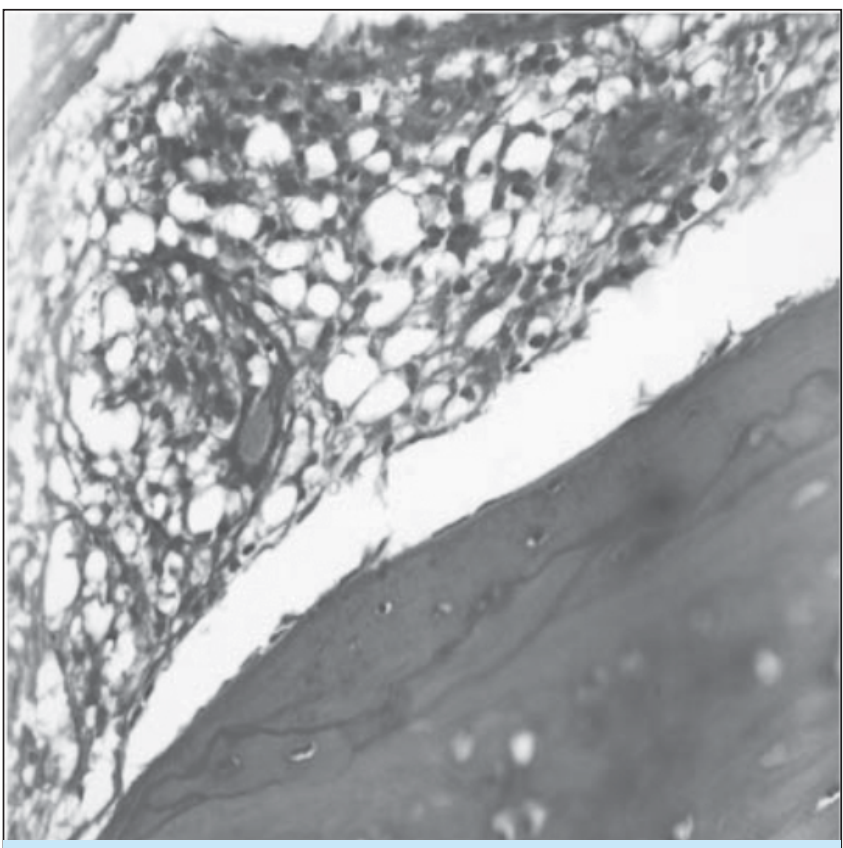

Fig-4. High power light microscopy view with bony trabeculae and intervening trabecular area exhibiting areas of histiocytic aggregates along with giant cells. (hematoxylin and eosin, 20x)

\section{DISCUSSION}

Tuberculosis remains a major problem despite advances and antituberculous therapy. Musculoskeletal tuberculosis is difficult to diagnose and can go unnoticed for a long time because sign and symptoms are very nonspecific and can include insidious onset of pain, swelling, weight loss, night sweats and difficulty in walking. During initial stage of disease laboratory tests like raised erythrocyte sedimentation rate, complete blood count are inconclusive and moreover radiologic appearance depend upon stage of 


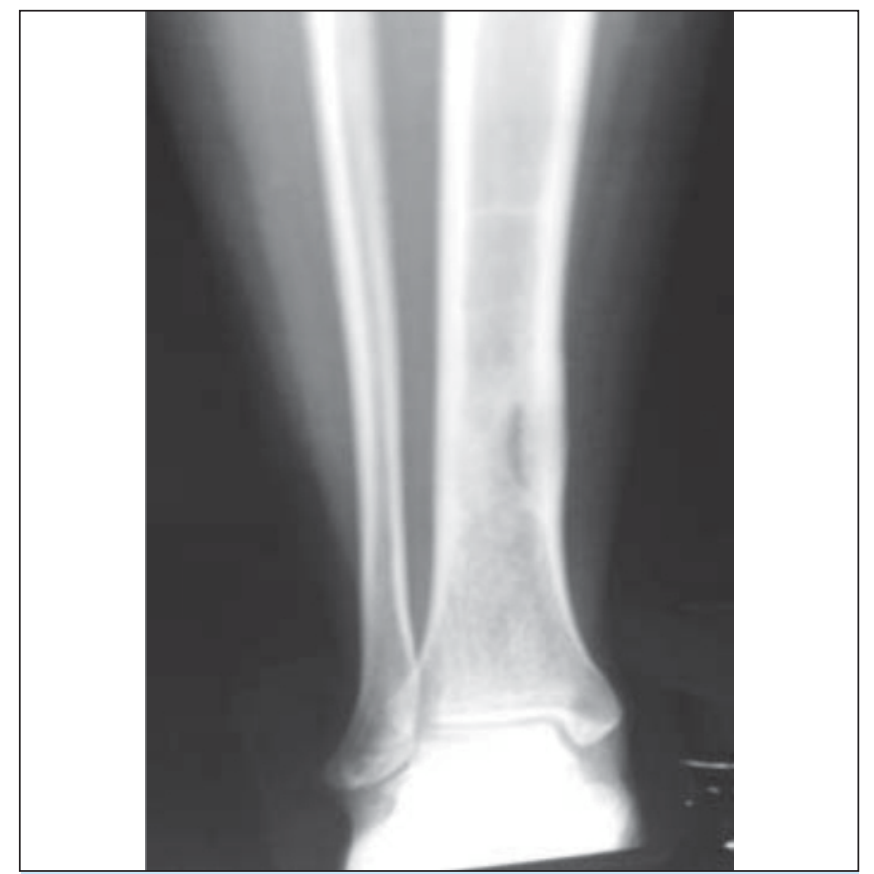

Fig - 5: X-Ray after 12 months of anti tuberculous therapy

disease on presentation. Primary diaphyseal TB of tibia without articular involvement is extremely rare and only few cases have been reported ${ }^{9}$. Jacob ${ }^{9}$ in a series of 30 cases of atypical TB in immigrants reported only 2 cases involving tubular bones. Carino(5) in his series of 15 cases reported $80 \%$ cases involving primarily the long bones(femur $=7$, tibia $=3$, humerus $=2$ ). Another case of diaphyseal TB of tibia was reported in 1983 by Richter ${ }^{7}$ in a study of 27 years. Chattopadhyay ${ }^{10}$ reported one male patient with primary diaphyseal TB of tibia. In our patient there was no previous history of pulmonary tuberculosis while in the literature one third of patients with skeletal tuberculosis reported to have pulmonary tuberculosis ${ }^{11,5}$.

\section{CONCLUSIONS}

Tuberculosis is a wide spread problem in our region. It should be considered as one of the differentials in the diagnosis of an osteolytic lesion in diaphysis of long bone.

Copyright(C) 10 Oct, 2014.

\section{REFERENCES}

1. Ridley N, Shaikh MI, Remedios D, Mitchell R. Radiology of skeletal tuberculosis. Orthopaedics. 1998 Nov;21(11):1213-20.

2. WHO Geneva report 2011. Global tuberculosis control WHO report 2011. LHP/who.int/tb/publications/global report 2011/gtr.

3. Mannepalli S, Mitchell-Samon L, Guzman N, Relan M, McCarter YS. Mycobacterium tuberculosis osteomyelitis in a patient with human immunodeficiency virus/acquired immunodeficiency syndrome (HIV/AIDS); A case report. Cases J. 2010 Feb 23;3:67.

4. Shikhare SN, Singh DR, Shimpi TR, Peh WC. Tuberculous osteomyelitis and spondylodiscitis. Semin Musculoskeletal Radio. 2011 Nov;15(5):446-58.

5. CarinoA.Aclinical profile offifteencases oftuberculous osteomyelitis seen at the Philippine Orthopaedic center. March5, 2009. http://www.thefreelibrary.com/_/ print/PrintArticle.aspx?id=1073936799.

6. Bodur $\mathrm{H}$, Bodur $\mathrm{H}$, Akinci $\mathrm{H}$, Yilmiz $\mathrm{O}$, Borman $\mathrm{P}$, Tanyolac $\mathrm{O}$ et al. Osteo-articular tuberculosis. Tuberk Toraks. 2003:51(4);424-31.

7. Richter R, Krause FJ. Primary diaphyseal tuberculosis of the long bones. Rofo. $1983 \mathrm{Nov} ; 135(5): 549-52$.

8. Akgul T, Ozger H, Göksan BS, Eren I. Cystic tranphyseal bone tuberculosis: a report of two cases. Acta Orthop Traumatol Turc 2012;46(4):316-19.

9. Jacob P. Osteo-articular tuberculosis in coloured immigrants. A radiological study. Clin Radiol. 1964;15:59-69.

10. Chattopadhyay P, Bandyopadhyay A, Ghosh S, Kundu AJ. Primary diaphyseal tuberculosis of the tibia. Singapore Med J. 2009;50(6);226.

11. Jason JA. Tuberculous Arthritis in Filipinos: A review; Philippine Journal of Orthopaedics Vol.12,Dec. 1993. 